\title{
URBAN HEAT ISLAND MICRO-MAPPING VIA 3D CITY MODEL
}

\author{
U. Ujang ${ }^{1, *}$, S. Azri ${ }^{1}$, M. Zahir ${ }^{1}$, A. Abdul Rahman ${ }^{1}$, T. L. Choon ${ }^{1}$ \\ ${ }^{1}$ Dept. of Geoinformation, Faculty of Built Environment and Survey, Universiti Teknologi Malaysia, Malaysia - \\ (mduznir, suhaibah, mzhir, alias, tlchoon)@utm.my
}

KEY WORDS: Urban Heat Island, 3D City Models, 3D Solar Analysis

\begin{abstract}
:
Urban Heat Island (UHI) phenomenon has been a topic of intense study over the past several years. However, to visualise UHI model is still an issue. Common visualisation of UHI by using digital thematic maps shows that it is hard to perceive its impacts especially in a sophisticated micro-area such as in urbanized cities. Moreover, different building façade's material gives different UHI value. Therefore, there is a need in computing and visualising this phenomenon in three-dimensional (3D) perspectives. Recently, the development of 3D city modelling shows the potential of solving these gaps. This can be seen from the characteristics of 3D city models that are suitable in representing micro-areas (complex cities) for UHI studies. Based on this issue, this research aims to produce a 3D UHI model by using 3D city models as a tool for efficient and sustainable building design. The main objective is to produce a new approach in visualising UHI in 3D perspectives by instigating 3D city models. Thus, the UHI effect could be predicted precisely by calculating the building façades value. This research explores the 3D shadow analysis, 3D solar radiation and $3 \mathrm{D}$ orientation analysis in UHI modelling via 3D city models. From the analyses, the results show that the 3D city models are capable in presenting the solar radiation value for each building façade. Furthermore, this approach can be used to simulate future UHI analysis-prediction and advantageous for pre-development planning.
\end{abstract}

\section{INTRODUCTION}

Urban Heat Island (UHI) is an increase of temperature in urban area that generates temperature differences between urban and rural area. Due to the replacement of vegetation with concrete, roads, buildings and other man made structure in urban areas, the temperature rise slightly higher compared with suburbs or rural areas with more trees or shrubs. This is due to this manmade structures absorb the sun's heat, causing surface temperatures and overall ambient temperatures to rise (Aflaki et al., 2015; Guattari et al., 2018; Schrijvers et al., 2015). Vegetation provides shading and evaporation from soil and leaves. Whereby, this creates natural cooling effect to the surrounding area. However, tall buildings and narrow streets cause heat air trapped between them and reduces the air flow. Furthermore, the waste heat from vehicles, factories, and air conditioners may add heat to the surroundings, further worsening the urban heat island effect (Costanzo et al., 2016; El-Hattab et al., 2017).

\subsection{Research Motivation}

The Urban Heat Island (UHI) phenomenon has been the topic of intense study over the past several years. There are several main causes determined in formation of UHI and several mitigation strategies were planning to reduce it. As for an example, Lawrence Berkeley National Laboratory (LBNL) published one of the first guidebooks titled "Reducing Urban Heat Island: Compendium Strategies - Cool Roofs" for urban heat island mitigation (Akbari, 2009). This book describes the causes and effect of UHI and promotes strategy for lowering temperature in United State. This guidebook emphasizes cool roof as one way to reduce the UHI in urban area. This shows that UHI is a serious problem need to be highlighted.
According to Elsayed (2012), the heat island impact can be reduced by producing a proper urban design (Elsayed, 2012). He also state the use of sufficient and properly spaced parks and the use of high reflectivity, low heat capacity and low heat conductivity building materials can weaken the heat island. On the other hand, dense concentrations of materials like asphalt and buildings absorb more heat during the day and release it more slowly at night compared with natural ground cover such as soil and vegetation (Taleghani et al., 2016). Based on these, it can be seen that building design is one of the main factors that can contribute to UHI phenomenon.

\subsection{Background Problem}

One of the factors that contribute to the rise of temperature in city area is the urban architectural design. The configuration of building in the city that is located close to each other will trap the radiation within the city (Elsayed, 2012). Multiple reflections between buildings and urban surfaces occur before the solar radiation is reflected to the space due to building height and cluster pattern. In addition, the size and height of buildings will reduce the sky view of the surface and hence limit the emission of thermal radiation to space. The wind flow or turbulent transports are also distracted by the overlapping buildings which are pervious surface too. Moreover, the building should not be painted with dark colour because of heat absorbance plus with the building exposure to sunlight for a long time during the day (Elsayed, 2012). So, the architectural design of a building are really important and need to be considered as it can gives an impact towards urban temperature.

Urban surface such as pavement and buildings reduce the natural surface like vegetation, crop and soil. The thermal properties of these two surfaces are significantly different. Urban fabric has much higher thermal capacity, thermal conductivity and albedo. Most of the buildings in the city are 
made up of concrete, glass, brick and asphalt. These types of materials can reflect some energy back to space but are also good at storing heat. As a consequence, urban surface absorb a huge amount of heat during daytime and slowly re-emit the stored heat during the late afternoon and night (Elsayed, 2012). These conclude that urban fabrics can influence the temperature rise in the urban area.

On the other hand, David (2007) stated that most of the UHI maps available today are of $2 \mathrm{D}$ variety (Schobesberger and Patterson, 2007). In this context, urban heat island mapping in 2D conventional map is not practical in mapping building which has height and complex shape. The 2D map only represents coordinates $(\mathrm{x}, \mathrm{y})$ but in planning the urban building design map we require height $(\mathrm{z})$ value. Besides, $2 \mathrm{D}$ map are too general and might be not accurate as it not show the detail design of the building and other features.

Recently, development in 3D city modelling gives new insight in future development planning. 3D city models can be defined as digital models of urban areas that signify terrain surfaces, sites, buildings, vegetation, infrastructure, landscape elements and features belonging to urban areas. It is really a reliable tool to be use in studying the urban heat island phenomenon as it has a few advantages compared to 2D conventional map. 3D modelling helps to visualize and understand elevation differences and topographic features (Schobesberger and Patterson, 2007). In building design context, 3D models can be view in the aspect of building height, structure configuration, materials and its colour than 2D map. Therefore, 3D city modelling can be a powerful tool to study the UHI phenomenon that is related to architectural building design and other urban heat island influence factor.

\section{UHI AND URBAN DESIGN}

Figure 1 shows the connection between UHI and urban building design. It is proven that urban forms affect urban microclimate (Givoni, 1998), and these changes in the urban environment will result in building energy consumption (Santamouris, 2013). As Oke (1982) argued, urban climatology can become a more predictive science in which findings can be of direct value in urban planning and design (Oke, 1982).

(Mills, 1999) proposed that by examining the relationship between urban forms and climate, one could employ the results of urban climatology into urban design guidelines. Therefore, for mitigating UHI effect by urban design, primary work on the research of urban forms is to systematically collect and comb all urban form factors that may impact building energy consumption.

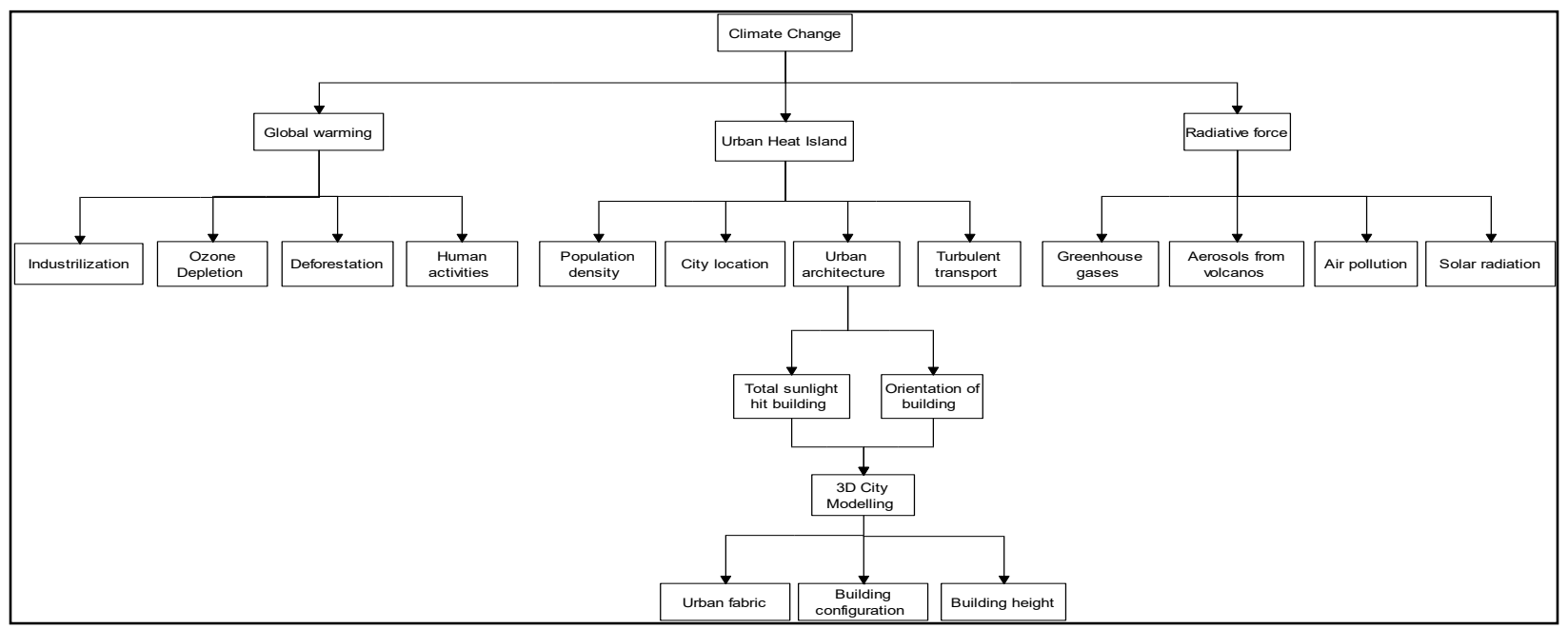

Figure 1. Connection between UHI and urban building design

\subsection{D City Model and UHI}

There is no doubt that the UHI is a growing problem in built-up environments, due to energy retention by the surface materials of dense buildings, leading to increased temperatures, air pollution, and energy consumption. To apprehend UHI, 3D information of the urban area surroundings is essential in order to analyse complex sites, including dense building clusters. 3D building geometry information can be combined with $2 \mathrm{D}$ urban surface information and it can examine the relationship between urban characteristics and temperature.

Building materials, such as concrete and asphalt, absorb thermal energy during daytime and release it during night-time cause the temperatures in dense building areas higher than in surrounding suburban and rural areas (Lei et al., 2016). Heat energy stored by complex urban structures are one of the core reasons of high surface temperatures is generated. The UHI adversely impacts urban populations, by inducing heat stresses and health problem, and worsening air quality through the formation of tropospheric ozone.

To improve our understanding on how urban characteristics influence the surface temperatures, we can analyse how much heat absorbs by the building using 3D model. To model this relationship, information such as materials of the building is being use for solar absorption analysis. Besides, geographic information which determines the location of the building can be used for orientation analysis.

\section{METHODOLOGY}

Three analyses were conducted; shadow analysis, solar absorption analysis and orientation analysis. These analyses are described briefly in the next subsections. 


\subsection{Shadow Analysis}

In this research, the study case used was buildings located in Precinct 3, Putrajaya, Malaysia. Putrajaya is officially the Federal Territory of Putrajaya, a planned city and the federal administrative centre of Malaysia. First of all, the shadow analysis should be done prior to other analyses mentioned in this paper. This is due to understand how the sun travel across the study area and finding which shadows are cast from surrounding objects and building. With these basic understanding, effective result could be gain in the analyses of solar absorption and orientation analysis.

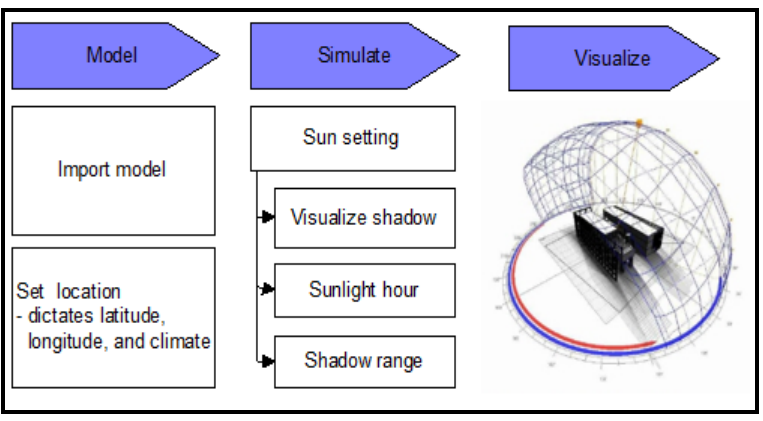

Figure 2. Shadow analysis method

Based on Figure 2, it can be seen that this analysis emphases on the sun's comportment over time. It shows where the shadow is at particular time (hour). Besides, shadow range can be used to see the pattern flow of the shadow. The range outlines being set at hourly interval over a day. This produces a pattern of shadows running from west to east. The result is helpful to visualize the full effect of the building on its neighbouring building.

\subsection{Solar Absorption Analysis}

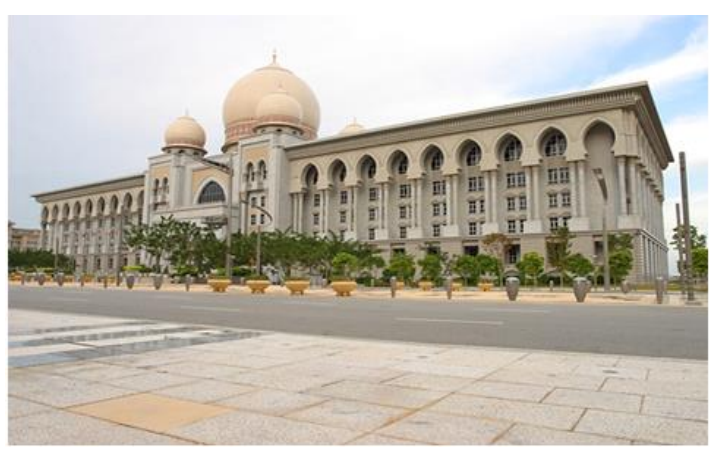

Figure 3. Palace of Justice building

This analysis will help to know in detail on how much the incident solar radiation will actually absorb by the building. These calculations do take into account material properties as each material has their own characteristic. To get accurate results, these properties must be ensuring definitely correct. For better view and understanding, this paper focuses on the Palace of Justice (POJ) building located in Precinct 3, Putrajaya (Figure 3) for this analysis.

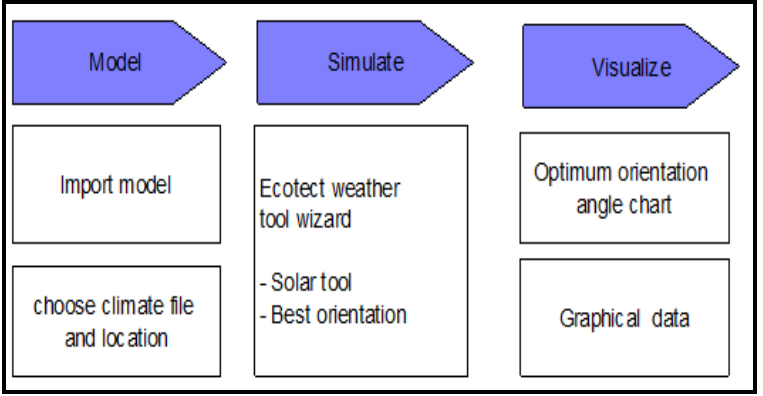

Figure 4. Solar absorption analysis method

In this study, solar absorption analysis use hourly recorded direct and diffuse radiation data from the climate file (as illustrated in Figure 4). As for this study, climate file use is Kuala Lumpur, Malaysia and coordinate system use is WGS 84. Time range use for this analysis is from 8:00 a.m. to 5:00 p.m. where will include the time when the sun is at its highest point in the sky at noon local time around 1:00 p.m. The time when the temperature are actually peak is around 3:00 p.m.

\subsection{Orientation Analysis}

Orientation analysis is useful in determining the optimum orientation angle of a building which can be used in city planning. If proposed building are oriented at an angle that is perpendicular to the prevailing wind, during intense UHI events this will reduce the chances of air circulation of the urban canyon and removal of heat and pollutants that accumulate between buildings.

This analysis gives information about orientation angle based on solar radiation and sun path. Based on this analysis, the building can be designed according to the produced result. This will gives a solar radiation at minimum amount.

\section{RESULTS AND ANALYSIS}

\subsection{Shadow Analysis}

The height of a building often gives a problem in a way that it blocks the other building from receiving the sunlight (Tablada and Zhao, 2016). This problem can be visualized using shadow analysis. By conducting the shadow analysis, we can see which building were block by other building at a certain time. The shadow range for a particular range time can be display. Besides, animate shadows are used to see the changes of shadow from time to time.

Shadows are visualized based on the sun's position. This is often a good starting point. It is important to see the effect of the building towards the surrounding building. As for examples, if a building is blocking another neighbouring building or the building were blocked by other buildings. Figure 5 shows the range for shadow analysis from 8:00 a.m. to 5:00 p.m. with hourly interval. In brief, this analysis shows the area of shadows of a particular area on a horizontal plane over time. 


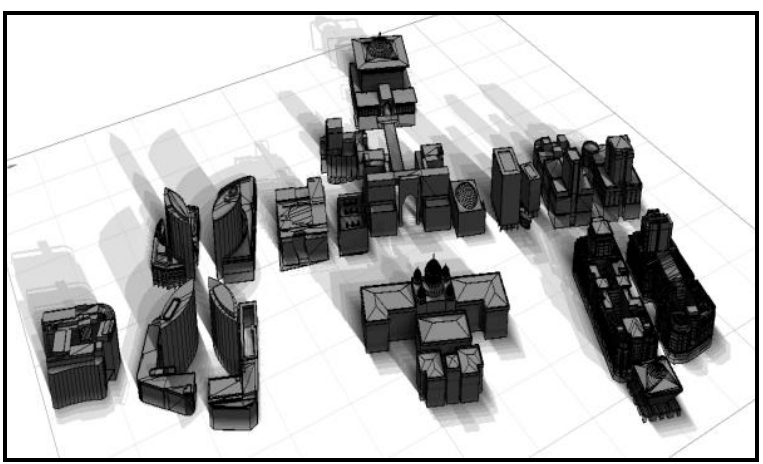

Figure 5. Shadow range from 0800 to 1700

\subsection{Solar Radiation Analysis}

Solar absorptance is a measure of the proportion of solar radiation a body absorbs. The higher the solar absorptance range, the more energy will be absorbed and body with high solar absorptance will reach higher temperature than one with lower solar absorptance. Energy that is absorbed is emitted by radiation and convection from all surfaces.

\subsubsection{Building materials}

In solar absorption analysis, besides the climate file and coordinate of the building, the building materials should be consider. The reason is that each type of materials has different capacity to absorb and store heat. In this research, the data for solar absorption is converted to GIS ready format (GIS database).

In this study, the heat absorb by the building are calculated for the duration of 8.00 a.m. to 5.00 p.m. Palace of Justice building is built from various type of materials which are plaster, heat retention foil, ceramic tile, concrete, asphalt and block plaster that have different solar absorption capacity. The solar absorption range is from 0 to 1 which 0 indicates the lowest solar absorption while 1 indicates the highest solar absorption.

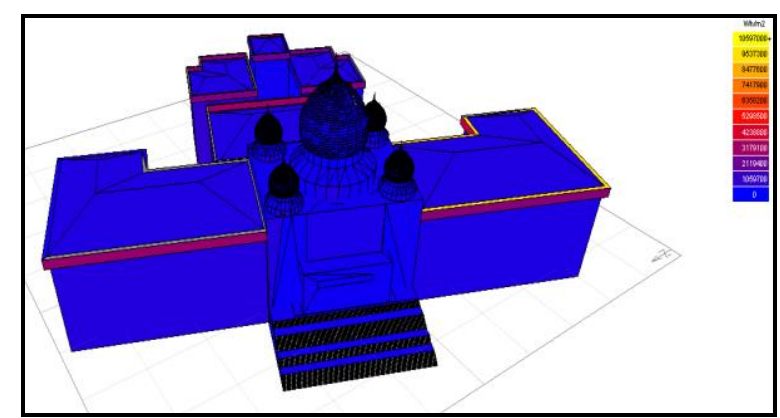

Figure 6. Solar absorb by Palace of Justice building

By using Ecotect software, the solar absorbed by Palace of Justice building are shown as in Figure 6. The figure shows the simulation of amount of solar absorb by each type of materials. Intense yellow values indicate warmer surface areas value. The total amount of solar absorbed seems identical for each material although there are some differences between them. Based on the observation, the similar amount of solar absorbed are caused by the equilibrium that reach between the materials as the time for this analysis was set from 8.00 a.m. to 5.00 p.m. which high amount of solar are received at that time.

\begin{tabular}{|l|l|l|l|}
\hline Item & Type of materials & Texture & $\begin{array}{l}\text { Solar } \\
\text { Absorption } \\
\text { Range (0-1) }\end{array}$ \\
\hline Dome & $\begin{array}{l}\text { Plaster, } \\
\text { Heat retention foil, } \\
\text { Ceramic tile }\end{array}$ & 0.548235 \\
\hline Roof & $\begin{array}{l}\text { Concrete, } \\
\text { Asphalt }\end{array}$ & & 0.900000 \\
\hline Wall & $\begin{array}{l}\text { Concrete, } \\
\text { Block Plaster, } \\
\text { Granite }\end{array}$ & & 0.506000 \\
\hline
\end{tabular}

Table 1. Materials properties of Palace of Justice building

The conductivity and reflectivity of the materials do affect the solar absorption. Each material used has fundamental physical properties that determine their energy performance like conductivity, resistance, and thermal mass. For solar absorption analysis, Palace of Justice building was used to determine the heat absorption from 8.00 a.m. to 5.00 p.m. Table 1 shows the materials properties for the building.

\subsubsection{GIS format ready}

The analysis result derived from Ecotect software can exported into a spreadsheet format. For further analysis, the data should be in GIS ready format. This will relate the information in geospatial database with the 3D model developed in ArcGIS.

The procedure for importing the results began with a manual extraction from the Ecotect result sets of solar absorption for the one month of simulation (Figure 7). Although the model generates a variety of outputs, such as total incident radiation and total transmitted radiation, only solar absorption have been used in geospatial database format (Figure 8).

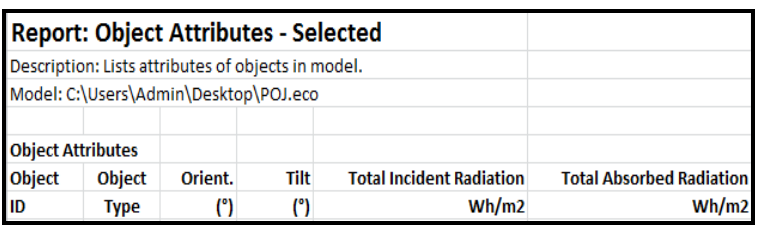

Figure 7. Information of total absorbed radiation generate from Ecotect software in spreadsheet format

\begin{tabular}{|c|c|c|c|c|c|c|c|}
\hline \multicolumn{8}{|c|}{ Solar_absorbtion } \\
\hline OID & OBJECTID & Object & Object_1 & Orient_ & Tilt & Total_Inci & \begin{tabular}{|l|} 
Total_Abso \\
\end{tabular} \\
\hline 1 & & 20 & Roof & 111.39 & -50.72 & 4490.943 & 347379.344 \\
\hline 2 & & 1 & Roof & 111.39 & \begin{tabular}{|l|l|} 
& -50.71 \\
\end{tabular} & 4502.512 & 348274.094 \\
\hline 3 & & 2 & Roof & 111.39 & \begin{tabular}{|l|l|} 
& -52.79 \\
\end{tabular} & 4545.021 & 351562.406 \\
\hline 4 & & 3 & Roof & 111.39 & -52.8 & 4553.471 & 352215.969 \\
\hline 5 & & 4 & Roof & -68.61 & -20.23 & \begin{tabular}{|l|l|l}
16498.121 \\
\end{tabular} & 1219852.75 \\
\hline
\end{tabular}

Figure 8. The information in geospatial database format 
Figure 9 shows the simulation of the solar absorption received by the building in ArcScene software. The roof, dome and wall has different range amount of heat absorbed. The roof absorbed the highest amount of energy followed by the dome and wall.

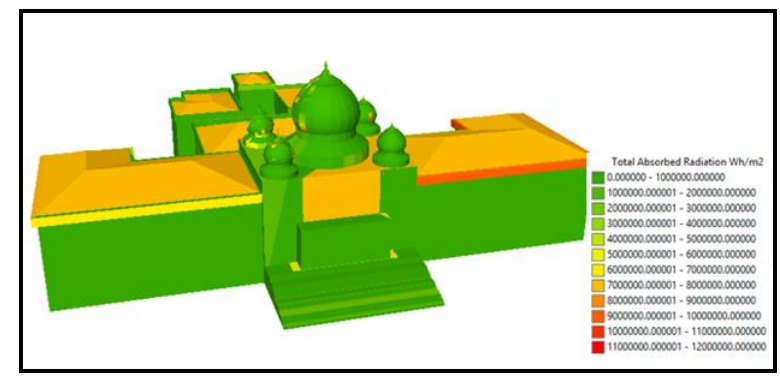

Figure 9. The simulation of solar absorption viewed in ArcScene

\subsection{Orientation Analysis}

Another important aspect that affects building performance is the building orientation. An effective passive solar heating design assumes that the building is orientated to receive as much solar radiation as possible when heating is required, whilst rejecting as much as possible when it is not.

To derive the most effective orientation, the Weather Tool calculates the amount of solar radiation incident on a $1 \mathrm{~m}^{2}$ vertical surfaces for each $5^{\circ}$ of orientation angle. Three values are stored for each angle, the average daily radiation taken over the whole year, over the coldest 3 months and over the warmest 3 months. These three values can then be plotted on a polar graph where the radius of any point from the centre represents the incident radiation value. Figure 10 shows an example of building orientation located at Kuala Lumpur, Malaysia.

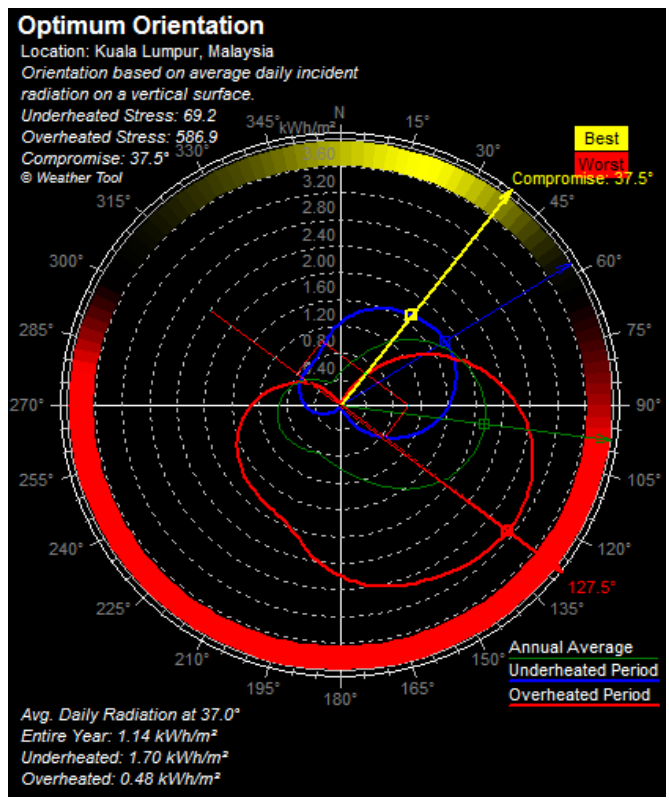

Figure 10. Optimum orientation angles based on solar radiation received in the coldest 3 months (blue), the warmest 3 months (red) and over the entire year (green)
The incident radiation on the east face in the morning and the west face in the evening is much greater than that on the north face during the middle of the day.

Figure 11 shows the original position of the building while Figure 12 shows the position after alteration according to the best orientation analysis that been computed. The difference can be seen as the heat absorbed by the alter building is less than the original. This is discussed in the next sub-section.

\subsection{Comparison of Solar Radiation Absorptance - After Orientation Change}

It is possible to lessen the solar radiation absorb by the building by changing the orientation. The orientation can help optimize the sunlight received. ArcScene 10.3 was used to simulate the heat absorbed by the building. Graduated colours from green to red were used to view the pattern of the heat absorbed.

Figure 13 shows the heat absorbed in original position of the building. The minimum heat absorbed by the building is 470 $\mathrm{W} / \mathrm{m}^{2}$ and the maximum heat absorbed is $353210 \mathrm{~W} / \mathrm{m}^{2}$. Meanwhile, the mean of heat absorbed are $49135 \mathrm{~W} / \mathrm{m}^{2}$. The roof, which are made up of concrete and asphalt absorbed the highest amount of sunlight that is $353210 \mathrm{~W} / \mathrm{m}^{2}$. It has the highest range of solar absorption capacity compared to other type of materials.

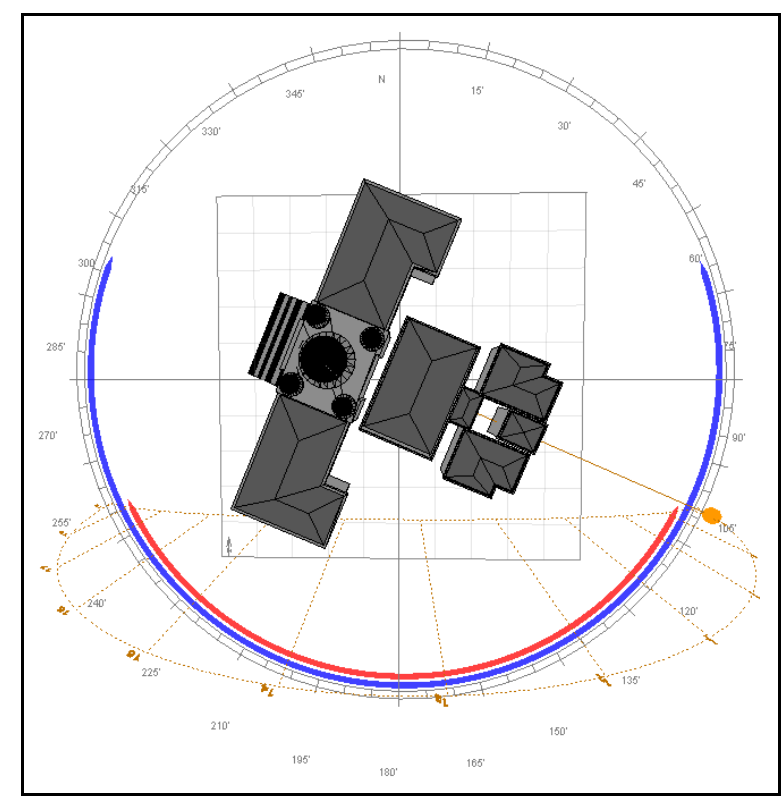

Figure 11. The original position of POJ building 


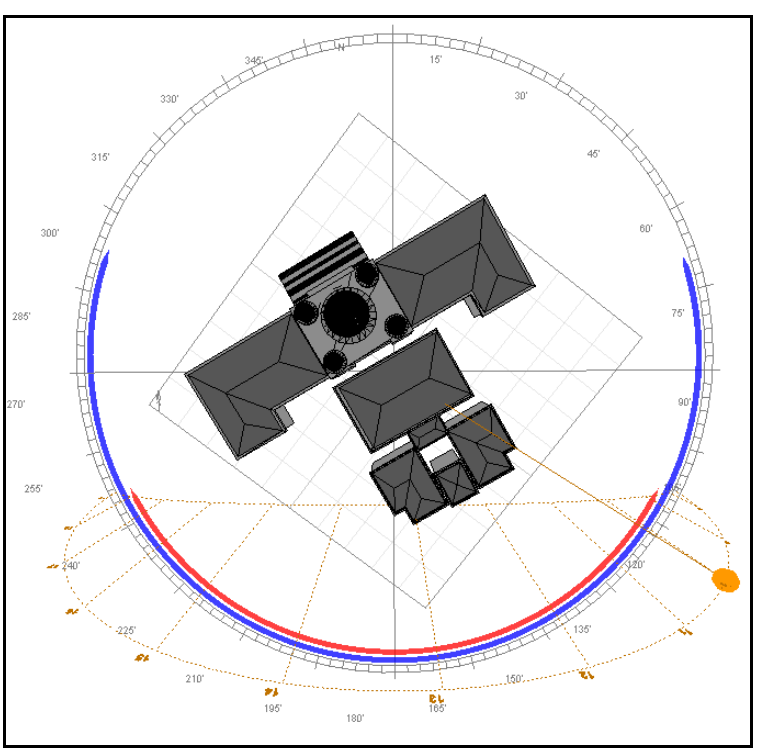

Figure 12. The position of POJ building after alteration of $37.5^{\circ}$

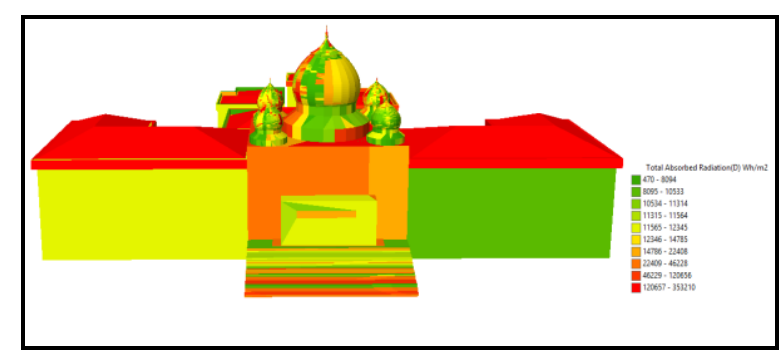

Figure 13. The simulation of heat absorb in original position

Figure 16 shows the heat absorbed in after the angle being changed by $37.5^{\circ}$. The minimum heat absorbed by the building is $3276 \mathrm{~W} / \mathrm{m}^{2}$ and the maximum heat absorbed is $352910 \mathrm{~W} / \mathrm{m}^{2}$. The mean of heat absorbed are $49075 \mathrm{~W} / \mathrm{m}^{2}$.

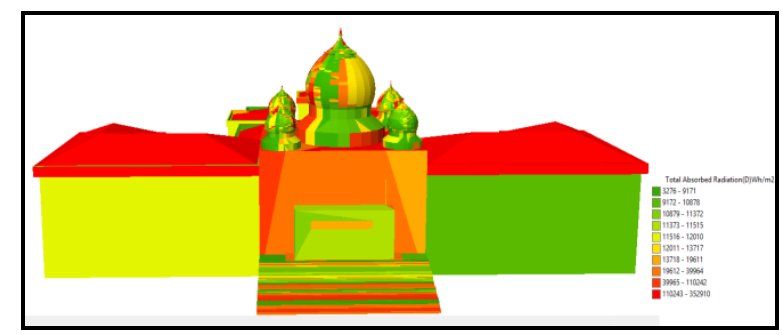

Figure 14. The simulation of heat absorb after alter the position

The heat absorbed at original orientation has low minimum value compared to heat absorbed at new orientation. However, its maximum value is higher than new orientation building. The mean for original position and altered position are $49135 \mathrm{~W} / \mathrm{m}^{2}$ and $49075 \mathrm{~W} / \mathrm{m}^{2}$ respectively. The mean of both analyses only has $60 \mathrm{~W} / \mathrm{m}^{2}$ difference.

There are only slightly change in solar absorption after the orientation of the building are changed. However, suggestions such as redesign the surrounding landscape by having more trees or plants will contribute to more changes in the building solar absorption. However, the new orientation still absorbs lower solar radiation than the original orientation and this might be different and can be studied for other types of climates.

\section{CONCLUSION}

From the research and analysis done, height material properties and orientation are the most important part for assessing sustainable buildings. This will determine the most optimum solar radiation for a building. The overall assessment shows that the height of the building should be suitable with the neighbouring building. Furthermore, the material properties should be considered carefully in the planning stage in order to reduce the UHI effect. The material must have low heat capacity, low heat conductivity and high reflectivity of solar radiation. The $3 \mathrm{D}$ city model has proved to be a practicable tool in visualising the UHI problems and great for sustainable city planning.

\section{ACKNOWLEDGEMENTS}

This work is partially supported by UTM Research University Grants, Vote Q.J130000.2527.11H78 and Vote Q.J130000.2527.15H49.

\section{REFERENCES}

Aflaki, A., Mahyuddin, N., Mahmoud, Z.A.-C., Baharum, M.R., 2015. A review on natural ventilation applications through building façade components and ventilation openings in tropical climates. Energy and Buildings 101, 153-162.

Akbari, H., 2009. Cooling our communities. A guidebook on tree planting and light-colored surfacing.

Costanzo, V., Evola, G., Marletta, L., 2016. Energy savings in buildings or UHI mitigation? Comparison between green roofs and cool roofs. Energy and buildings 114, 247-255.

El-Hattab, M., Amany, S., Lamia, G., 2017. Monitoring and assessment of urban heat islands over the Southern region of Cairo Governorate, Egypt. The Egyptian Journal of Remote Sensing and Space Science.

Elsayed, I.S., 2012. Mitigation of the urban heat island of the city of Kuala Lumpur, Malaysia. Middle-East Journal of Scientific Research 11, 1602-1613.

Givoni, B., 1998. Climate considerations in building and urban design. John Wiley \& Sons.

Guattari, C., Evangelisti, L., Balaras, C.A., 2018. On the assessment of urban heat island phenomenon and its effects on building energy performance: A case study of Rome (Italy). Energy and Buildings 158, 605-615.

Lei, J., Yang, J., Yang, E.-H., 2016. Energy performance of building envelopes integrated with phase change materials for cooling load reduction in tropical Singapore. Applied Energy $162,207-217$.

Mills, G., 1999. Urban climatology and urban design. ICBICUC 99, 15th.

Oke, T.R., 1982. The energetic basis of the urban heat island. Quarterly Journal of the Royal Meteorological Society 108, 124.

Santamouris, M., 2013. Energy and climate in the urban built environment. Routledge. 
Schobesberger, D., Patterson, T., 2007. Evaluating the effectiveness of $2 \mathrm{~d}$ vs. 3d trailhead maps, Proc. 6th ICA Mountain Cartography Workshop, p. 201.

Schrijvers, P., Jonker, H., Kenjereš, S., de Roode, S., 2015. Breakdown of the night time urban heat island energy budget. Building and environment 83, 50-64.

Tablada, A., Zhao, X., 2016. Sunlight availability and potential food and energy self-sufficiency in tropical generic residential districts. Solar Energy 139, 757-769.

Taleghani, M., Sailor, D., Ban-Weiss, G.A., 2016. Micrometeorological simulations to predict the impacts of heat mitigation strategies on pedestrian thermal comfort in a Los Angeles neighborhood. Environmental Research Letters 11, 024003. 